\title{
Garci Rodríguez de Montalvo, Le Livre III d'Amadis de Gaule. Traduit par Nicolas Herberay des Essarts
}

\section{Michele Mastroianni}

\section{(2) OpenEdition}

1 Journals

\section{Edizione digitale}

URL: http://journals.openedition.org/studifrancesi/3691

DOI: 10.4000/studifrancesi.3691

ISSN: 2421-5856

\section{Editore}

Rosenberg \& Sellier

\section{Edizione cartacea}

Data di pubblicazione: 1 décembre 2012

Paginazione: 554-555

ISSN: 0039-2944

\section{Notizia bibliografica digitale}

Michele Mastroianni, «Garci Rodríguez de Montalvo, Le Livre III d'Amadis de Gaule. Traduit par Nicolas Herberay des Essarts», Studi Francesi [Online], 168 (LVI | III) | 2012, online dal 30 novembre 2015, consultato il 07 mars 2021. URL: http://journals.openedition.org/studifrancesi/3691 ; DOI: https:// doi.org/10.4000/studifrancesi.3691

Questo documento è stato generato automaticamente il 7 mars 2021.

\section{(c) $(1) \odot$}

Studi Francesi è distribuita con Licenza Creative Commons Attribuzione - Non commerciale - Non opere derivate 4.0 Internazionale. 


\title{
Garci Rodríguez de Montalvo, Le Livre III d'Amadis de Gaule. Traduit par Nicolas Herberay des Essarts
}

\author{
Michele Mastroianni
}

\section{NOTIZIA}

GARCI RODRíGUEZ DE MONTALVO, Le Livre III d'Amadis de Gaule. Traduit par Nicolas Herberay des Essarts, édition de Michel BIDEAUX, introduction de Luce et Jean-Pierre GUILLERM, Paris, Classiques Garnier, 2011 («Textes de la Renaissance», 172), pp. 408.

1 Continua la monumentale impresa dell'edizione critica della traduzione francese cinquecentesca dell'Amadís de Gaula. Dopo la pubblicazione del V libro (cfr. questi «Studi», 150, 2006) e del I libro (cfr. questi «Studi», 154, 2008), abbiamo ora il III libro, tradotto sempre da Herberay des Essarts, nell'edizione critica di Michel Bideaux. I criteri sono quelli stabiliti nell'edizione del I libro. L'introduzione di L. e J.-P. GUILLERM (pp. 9-39) mette in evidenza le caratteristiche del III libro. Il campo d'azione allarga i suoi confini e l'avventura si sposta verso l'Oriente mediterraneo. Il III libro, ancor più dei primi due segna l'esaurimento della vena cavalleresca e il suo rinnovamento con l'introduzione di nuovi interessi. I prefatori sottolineano, comunque, come, rispetto agli italiani che hanno rinnovato il genere cavalleresco, Boiardo e Ariosto, che sovrabbondano nella moltiplicazione degli episodi e nell'introduzione del meraviglioso, Montalvo sia molto più sobrio, concentrando l'attenzione su Lisuart e sulle sue vittime, Amadis e Oriane. L'arcaismo cavalleresco suscita meno nostalgia, e, in questo caso come in Boiardo e Ariosto, si manifesta una cultura più fine, sensibile all'umorismo e all'ironia. Come ben evidenziano i prefatori, in questo libro "si manifesta come un appello discreto a un'intelligenza moderna che si potrebbe definire 'critica' se l'obiettivo di fondo non rimanesse quello del piacere». L'annotazione puntuale, gli 
accurati indici (ragionato dei personaggi, dei toponimi, tematico) e la ricca e aggiornata bibliografia, rendono questa edizione rigorosa un ottimo strumento di consultazione. 